\title{
Analysis on the Vulnerability of Natural Disasters in Coastal Cities and Assessment of the Construction of Flexible Cities
}

\author{
Kaiyuan Wang ${ }^{1}$ MaoNing $\mathrm{He}^{2}$ \\ Safet Risk Control Technology Research Institute \\ Qingdao,China \\ wangkaiyuan@sft360.com \\ 沿海城市自然灾害脆弱性分析与 \\ 㓞性城市建设评估 \\ 王凯媛 ${ }^{1}$ 何茂宁 ${ }^{2}$ \\ 赛飞特风险防控技术研究院 \\ 青岛 266100 ，中国 \\ wangkaiyuan@sft360.com
}

\begin{abstract}
With the expansion of urban population and economic development, the hidden dangers of disasters are increasing, and the disaster factors are constantly expanding and intensifying. Especially in coastal cities, because of the interaction between climate and land and sea, coastal cities are both pregnant and disaster-bearing. The National Plan for Comprehensive Disaster Prevention and Mitigation (2016-2020) states that the complex and volatile disaster situation in China and the weak foundation for disaster prevention and reduction require us to take a long-term, holistic and changing view of urban development. We will continue to improve the ability of cities to adapt to and transform against natural disasters and risks. Therefore, the study on the vulnerability and resilience of coastal cities to natural disasters is of great significance to improve the resilience and resilience of cities.
\end{abstract}

Keywords-Vulnerability of Natural Disasters, Assessment of Flexible Cities, coastal cities

摘要一随着城市人口的扩张、经济的发展, 灾害隐患不断增多, 致灾因素更是不断外延、激化。
尤其是沿海城市，由于气候和海陆的交互作用，使 得沿海城市既是孕灾体, 又是承灾体。《国家综合 防灾减灾规划》（2016-2020）指出，我国灾情形势 复杂多变, 且防灾减灾救灾基础薄弱, 需要我们以 长远、全局、变化的眼光来看待城市的发展, 不断 提高城市应对自然灾害和风险的适应和转型能力。 因此，对沿海城市自然灾害脆弱性以及㓞性城市的 研究对提高城市抵御自然灾害影响, 提高自身恢复 能力有重要意义。

关键词一一自然灾害脆弱性, 㓞性城市评估, 沿 海城市

\section{I . 引言}

我国沿海地区共包含 9 个省, 2 个直辖 市，53 个城市，以 $13 \%$ 的国土面积，承载 大于 $50 \%$ 的人口, 拥有 $80 \%$ 的生产总值, 是 我国人员、资源、财产最为集中的区域。

随着城市人口的急剧扩张, 受气候变化、 海平面上升等影响, 我国沿海地区面临着台 风、暴雨、风暴潮、海啸等自然灾害风险。 如 2004 年 8 月份, “云娜” 肆虐浙江 15 个 小时, 导致全省死亡 164 人; 2019 年 4 月份, “4 - 11 深圳短时极端强降水天气” 使 16 
名在地下暗渠作业的人员被冲走。沿海地区 的自然灾害所造成的危害已不容忽视。

目前, 对于沿海地区的自然灾害研究不 断深入, 在气候变化与社会发展的背景下, 沿海城市面对自然灾害的适应性与抵御能 力成为研究焦点。本文从 “沿海城市自然灾 害脆弱性”与 “㓞性城市建设” 两方面来对 沿海城市自然灾害进行分析。

\section{II 。自然灾害脆弱性}

“脆弱性”这一概念最早出现在自然灾 害领域的研究当中, 目前已扩延到经济学、 生态学、社会学等领域当中。当前在安全领 域的研究中, 对 “脆弱性” 内涵有不同的理 解，如适应性、应对能力、敏感性、弹性、 恢复能力等。总体来说, 脆弱性可理解为“系 统易受到不良影响的倾向或习性”。

在自然灾害方面，需要引入 “灾害系统 论” 的概念, “灾害系统论” 认为灾害系统 由致灾因子、孕灾环境与承灾体组成。致灾 因子、孕灾环境与承灾体三者之间并非独立， 而是相互关联。其中任何一个部分的变化, 都会影响灾害系统的变化。

“自然灾害脆弱性” 是从 “脆弱性” 概念上引申而来的。“自然灾害脆弱性” 指 城市社会经济系统在受到自然灾害影响时 抗御、应对和恢复的能力, 承灾体面对自然 灾害表现出的易于受到伤害和损失的性质, 这种性质是自然孕灾环境与人类活动相互 作用的综合产物, 反映的是沿海城市系统受 自然灾害影响、威胁的程度。

就青岛地区来说, 存在的自然灾害致灾 因子主要有台风、洪涝、风霞、低温冷冻、 干旱等气象灾害; 地震灾害, 山体滑坡、泥 石流等地质灾害; 风暴潮、绿潮等海洋灾害; 森林火灾和重大生物灾害等自然灾害及其 次生衍生灾害。

沿海城市脆弱性作为城市的一种重要 属性, 受多重影响因素影响, 以“灾害系统 论”为基础, 对沿海城市 “自然灾害脆弱性” 建立指标体系, 我们以三个指标体系, 即暴 露度、敏感性、适应能力, 进行沿海城市自 然灾害脆弱性的分析。

(1) 暴露度: 人员、环境和各种资源、 基础设施以及经济、社会或文化资产处在有
可能受到不利影响的位置。如人口暴露度、 建筑暴露度、财产暴露度等。

（2）敏感性：城市系统受到外部扰动 下, 系统可能产生的变化。如自然环境敏感 性、系统 (老旧社区、基础设施) 敏感性等。

(3) 适应能力: 城市系统在不利影响 中复原或适应不利影响的能力。如合理的规 划以及有效的管理措施、应急响应机制等。

在建立指标体系的基础上, 对各指标体 系建立指标因子，对各因子进行分析，可以 初步得到以下结论:

基础设施水平高, 经济实力强, 经济结 构合理, 人口结构合理, 人口数量适中, 城 市形态合理，灾害管理体制合理，公众参与 度越高的地区，脆弱性越低。沿海地区自然 灾害脆弱性分析不仅有利于防灾减灾, 也有 利于国家对下一步国民经济发展布局进行 调整，促进区域协调发展。

III . 㓞性城市建设

在 2002 年, ICLEI 联合国可持续发展 全球峰会上提出 “韧性” 概念; 2012 年, 联 合国减灾署启动亚洲城市应对气候变化韧 性网络; 2013 年，洛克菲洛基金会启动 “全 球 100 㓞性城市” 项目, 中国黄石、德阳、 海盐、义乌四座城市成功入选; 2016 年, 第 三届联合国住房与可持续城市发展大会, 将 倡导 “城市的生态与韧性” 作为新城市议程 的核心内容之一。目前, 韧性城市的研究还 处在一个全新的阶段。

“韧性” 可以概括为: 城市面对干扰、 冲击或不确定性因素的抵抗、吸收、适应和 恢复能力。可以将其比作人体的免疫系统, “㓞性” 程度越高, 在发生疾病或遇到伤害 时, 抵御能力和自我恢复能力越强, 不易受 到外来伤害; 而对于 “㓞性” 程度低的系统 来说, 遇到难以抵御的外来伤害时, 更有可 能一病不起。如 2012 年 10 月, “桑迪” 风县 风袭击美国, 导致电力, 交通瘫疾, 影响当 地的正常生活。

目前, “㓞性城市” 有以下几个方面的 含义:

（1）多样性（Diversity）：城市中有许 多功能不同的系统, 在面对突发事件时, 有 更多解决问题的能力和方法, 提高系统抵御 
多种威胁的能力

（2）圥余性 (Redundancy): 具有相同 功能的可替换的系统, 通过多重备份来增加 抵御突发事件时，系统的可靠性;

（3）恢复力（Recovery）：具有可逆性 和还原性, 受到冲击后仍能回到系统原有的 结构或功能;

（4）鲁棒性（Robustness）: 亦称稳健 性, 系统抵抗和应对外部冲击的能力

(5) 适应性 (Adaptation): 系统根据 环境的变化调节自身的形态、结构或功能, 以便于环境相适应, 减少受到的冲击。

此外, “韧性城市” 还具有智慧性、迅 速性、学习性等特点。

与应急体系建设与综合防灾减灾规划 相比较, 韧性城市建设的内涵更加丰富, 涉 及自然、经济、社会等各个领域。而且, 更 注重通过软硬件相互结合、各部门相互协调。 应急体系建设侧重于对突发事件的应急响 应和紧急救援, 韧性城市规划强调在提高系 统自身抵御能力的同时, 全面增强其适应性 和创新性; 㓞性城市建设将防灾减灾的职能 向后端延伸, 提升城市系统受到冲击后的恢 复、重组和学习能力。

㓞性城市的研究更强调城市系统对各 种风险的适应、恢复和学习转化能力。韧性 城市建设相较之前的城市建设来说, 有以下 的转变: 由单尺度、描述性分析到多尺度、 机理性评估, 由单部门抵御风险到动员全社 会力量协同作战, 由在最短时间内恢复原状 的工程思想转变为在较长时期内不断更新、 协同进化的生态思想, 由被动的应急响应转 变为主动的规划调控, 由刚性的抵御对抗转 变为柔性消解转化。

\section{IV．韧性城市评估}

韧性城市评估工作目前未形成系统的 体系, 仅在本文中结合实际工作经验, 根据 城市安全评估工作, 提出以下韧性城市评估 工作思路。

（1）以国内权威认可的清华大学公共 安全研究院建立的 300 余种致灾因子的全要 素数据库为基础, 除去当地城市未涉及的因 子, 结合网络大数据挖掘与应急预案, 遴选 频率高, 影响大的主要的灾害类型。
（2）通过安全评价、风险评估、数学 模型以及计算机技术建立城市风险评估体 系, 对城市中存在的风险点为基础, 对主要 突发事件的波及范围及其可能造成的人员 伤害等进行定量、定性评估和预测。且识别 典型灾害之间的内在关联性，构建不同风险 源的耦合关系矩阵, 进行风险的识别与评估。

（3）在风险识别与评估的基础上，对 城市风险区域进行划分，可借鉴目前城市安 全四色图，绘制城市综合风险地图，篮选高 风险区域进行分析。

（4）评估城市韧性。城市韧性可从两 个方面进行考量, 分别是城市硬件, 即城市 系统; 城市软件, 即城市管理。城市系统评 估中，可将房屋建设质量、人员受教育、基 尼系数、避难场所建设、轨道交通等作为评 估因子; 城市管理评估中, 可将领导力水平、 职责组织、专项预算和投入、风险普查、应 急管理体系建设等等作为评估因子。

通过定性和定量相结合的方法, 评估城 市的现状管理水平和未来发展方向, 进而确 定相应的规划策略以强化城市韧性。

$$
\text { V . 思考 }
$$

根据现有国外有关城市适应气候变化 的研究成果, 结合我国沿海城市特点, 需要 深入考虑以下问题:

（1）需要通过对气候变化的自然基础 深入把握的基础上, 识别脆弱地区, 进行㓞 性管理与评估;

（2）考虑不同层次、不同尺度的气候 变化适应策略, 建立区域一城市一社区各层 次的气候变化治理相关的协定、法规、政策、 策略等。沿海地区自然灾害下沿海城市的脆 弱性与韧性研究所涉及的专业知识非常庞 杂, 因此, 利用多学科方法、交叉进行研究 显得格外重要。

（3）灾害数据是城市自然灾害风险研 究的基础, 进一步收集、整合各种基础地理 信息数据、社会经济数据、灾情数据, 建立 城市自然灾害综合风险研究的灾害数据库, 为城市自然灾害风险研究奠定基础。

（4）遥感技术、GIS 技术、InSAR 技 术的应用。未来, 在灾害风险的可视化表达, 数字高程模型建立以及地表位移监测的综 
合动态评估中, 以上技术的应用可以很大程 度上帮助到相关研究。

参考文献

[1] 李鹤, 张平宇, 程叶青. 脆弱性的概念及其 评价方法[J].地理科学进展.2008,(02):18-25.

[2] Turner II B L, Kasperson R E, Matson P A, et al. A frame-work for vulnerability analysis insustainability science.Proceedings of the National Academy of Sciences of the United States of America, 2003, 100(14): 8074-8079.

[3] 王松华, 赵玲.城市脆弱性综合评价体系 建构研究 $[\mathrm{J}]$. 苏州大学学报(哲学社会科学 版).2014,(05):30-37.

[4] Wang Xiaodan, Zhong Xianghao. Approaches to concept of vulnerability of ecology and environment. Journal of Mountain Science, 2003, 21: 21-25.

[5] Yao Jian, Ai Nanshan, Ding Jin. Progress in the studies of eco-environmental fragility and assessment in China. Journal of Lanzhou University (Natural Sciences), 2003, 39(3): 77-80.

[6] Huang Chongfu. Natural Disaster Risk Analysis. Beijing: Beijing Normal University Press, 2001.

[7] 苏桂武, 高庆华. 自然灾害风险的行为 主体特性与时间尺度问题. 自然灾害学报, 2003, 12(1): 9-16.

[8] Mc Fadden L, Vafeidis A, Nicholls R J. A Coastal Database for Global Impact and Vulnerability Analysis. $5^{\text {th }}$ International Symposium on Coastal Engineering and Science of Coastal Sediment Processes: Coastal Sediments '03, Clearwater Beach, Florida, USA, 18-23 May 2003. 